\title{
Case - Combined endoscopic cautery and over-the-scope-clip closure of an acquired rectourethral fistula: A novel surgical repair technique
}

Justin D. Oake, MD ${ }^{1}$; Darrel E. Drachenberg, MD, FRCSC ${ }^{1}$; David Hochman, MD, FRCSC ${ }^{2}$

${ }^{1}$ Department of Surgery, Section of Urology, University of Manitoba, Winnipeg, MB, Canada; ${ }^{2}$ Department of Surgery, Section of General Surgery, University of Manitoba, Winnipeg, MB, Canada

Cite as: Can Urol Assoc J 2018 October 15; Epub ahead of print. http://dx.doi.org/10.5489/cuaj.5624

Published online October 15, 2018

$* * *$

\section{Introduction}

In 2012, prostate cancer was the most frequently diagnosed cancer among males in Canada and accounted for $23.4 \%$ of all new cancer cases diagnosed. ${ }^{1}$ The standard of care for localized prostate cancer is radical prostatectomy (RP). Other therapeutic interventions include radiotherapy (external beam radiotherapy [EBRT] or brachytherapy [BT]), androgen deprivation therapy, and high intensity focused ultrasound (HIFU). ${ }^{2}$

The adverse effects of prostate cancer treatments include, but are not limited to, urinary incontinence, erectile dysfunction, bladder neck contracture, urethral stricture, irradiation cystitis, proctitis, enteritis, and rarely rectourethral fistulas (RUFs). ${ }^{3}$ RUFs are uncommon, approximately less than $2 \%$ of patients are at risk of RUF following primary prostate cancer treatment (RP, EBRT, or BT). ${ }^{4}$

We present the first use of an endoscopic closure technique by using a combination of over-the-scope clip (OTSC) and electrocautery for RUF repair. We hypothesize that electrocautery of the fistula tract de-nudes/de-epithelializes the fistula tract. This subsequently creates superficial inflammation and promotes bridging scar formation enabling successful fistula closure. Furthermore, combining electrocautery of the fistula tract with an OTSC also allows the user to grab more tissue and utilize the significant compressive force of the OTSC.

\section{Case reports}

\section{Patient 1}

A 67 year-old male who was diagnosed with prostate cancer, Gleason Score 3+4=7, underwent a retropubic RP with bilateral lymphadenectomy and developed an iatrogenic RUF. He was stooling relatively large amounts into his Foley catheter and urine through his rectum. His initial computed tompography (CT) scan did not visualize the fistula, however, repeat imaging 
documented a connection between the rectum and urethra. On digital rectal exam, there was a significant sized opening which was palpable, approximately $1 \mathrm{~cm}$ in diameter. Due to the very large size of the fistula tract, it was thought to unlikely heal with conservative management alone and he subsequently underwent a laparoscopic diverting loop ileostomy.

Post-operatively, a contrast barium enema showed persistence of the RUF (Fig. 1). Given the failure of conservative management, the decision was made for definitive surgical repair. A video endoscope was inserted and the fistula itself was visualized at approximately $7 \mathrm{~cm}$ from the anal verge in the anterior position. Biopsy forceps were advanced through the fistula tract itself confirming that it was in fact the fistula of concern. Electrocautery was then used to denude the fistula tract and the surrounding mucosa around the site. An OTSC was applied to the end of the endoscope which was then deployed with the fistula in the direct center of the cap with excellent coverage over the fistula itself (Fig. 2). The endoscope was then removed and the patient transferred to the recovery room in stable condition.

After six weeks of follow-up, a water soluble contrast enema was normal with no evidence of the RUF (Fig. 3). At a three month clinic follow-up visit, the patient stated that he was still asymptomatic, not passing stool or gas with urination, indicating his fistula remained closed. He still remains asymptomatic and radiographically healed at present, approximately 22 months post-procedure.

Patient 2

A 70-year-old male diagnosed with prostate cancer, Gleason Score 4+3=7, underwent HIFU. Postoperatively, the patient did quite well, however, six years later he developed biochemical recurrence. He subsequently underwent 12 months of androgen deprivation therapy followed by repeat HIFU. He developed an iatrogenic RUF, confirmed with voiding cystourethrogram. Given that the RUF persisted despite months of conservative management, the decision was made for definitive surgical repair.

A video endoscope was inserted and the fistula itself was visualized. Biopsy forceps were advanced through the fistula tract itself confirming that it was in fact the fistula of concern. Electrocautery was then used to denude the fistula tract and the surrounding mucosa around the site. An OTSC was applied to the end of the endoscope which was then deployed with the fistula in the direct center of the cap with excellent coverage over the fistula itself. The endoscope was then removed and the patient transferred to the recovery room in stable condition.

After eight weeks of follow-up, the patient stated that he had remained asymptomatic, with no urine with defecation and no stool present in his urine. A voiding cystourethrogram did note some contrast within the distal aspect of the anal canal, however, a direct communication from the urethra into the anal canal could not be ascertained. He still remains asymptomatic at present, approximately 15 months post-procedure. 


\section{Discussion}

In a study which reviewed acquired RUFs in adults, approximately $85 \%$ of surgical related RUFs were due to RP, and $40 \%$ of patients had a history of pelvic irradiation and/or ablation. ${ }^{5}$ Recent studies examining patients who have been treated with HIFU for localized prostate cancer have observed RUFs in 1.0-1.2\% of patients. There was also an increased risk of RUF following salvage HIFU (3.0-4.5\%). ${ }^{2,6}$

A minimally invasive endoscopic approach, compared to traditional surgical methods, has benefits including shorter inpatient stay, decreased morbidity and mortality, and being able to tolerate oral diet sooner. ${ }^{7}$ Recent studies have used traditional endoscopic clips for repair of gastrocutaneous fistulas with mixed success. Fistula closure rates ranged from $63-82 \%{ }^{8-10} \mathrm{~A}$ new endoscopic instrument, the OTSC developed by Kirschniak and colleagues, ${ }^{11}$ was developed to treat severe gastrointestinal bleeding, deep wall lesions, or perforations of the gastrointestinal tract. It is mounted on the distal tip of an endoscope. This new instrument allows much more powerful clips to be applied, compared to traditional endoscope clips. Consequently, OTSCs can grasp more tissue, including the entire thickness of the visceral wall, and apply a greater compressive force. Recent studies have utilized OTSCs and applied them to similar pathology. They have been used to treat a variety of gastrointestinal fistulas, including RUFs, gastrocutaneous fistulas, rectovesical fistulas, and tracheoesophageal fistulas. ${ }^{7,11-13}$ In four instances, electrocautery has been used in conjunction with either a traditional endoscopic clip or an OTSC to treat a fistula. Successful fistula closure rates ranged from 63-100\%.

OTSCs, without combined electrocautery of the fistula tract, have been used to treat RUFs caused by radical prostatectomy on two previous occasions. Both cases resulted in unsuccessful closure of the fistula. ${ }^{14,15}$ In our two cases of RUF repair, we have combined the use of electrocautery of the fistula tract with an OTSC and have had no clinical recurrence of the fistula (follow-up duration 15-22 months). The technique of combined endoscopic OTSC with electrocautery of the fistula tract described in this study is a promising alternative to invasive surgical treatments of RUFs. The use of endoscopic closure spares the patient the potential morbidity associated with surgical laparotomy and includes the option to perform the procedure with intravenous sedation in an outpatient setting. According to our initial experience, this is a simple and safe method for the management of RUFs detected after RP. Experience with more patients will be required to determine the long-term success and the best candidates for our combined technique closure. 


\section{References}

1. Ellison L. Prostate cancer trends in Canada, 1995 to 2012. Statistics Canada 2016.

2. Lukka H, Waldron T, Chin J, et al. Genitourinary Cancer Disease Site Group of Cancer Care Ontario's Program in Evidence-Based Care. High-intensity focused ultrasound for prostate cancer: A systematic review. Clin Oncol (R Coll Radiol) 2011;23:117-27.

3. Mundy AR, Andrich DE. Posterior urethral complications of the treatment of prostate cancer. BJU Int 2012;110:304-25.

4. Anderson KM, Gallegos M, Higuchi TT, et al. Evaluation and management of rectourethral fistulas after prostate cancer treatment. Curr Bladder Dysfunct Rep 2015;10:132-37.

5. Hechenbleikner EM, Buckley JC, Wick EC. Acquired rectourethral fistulas in adults: A systematic review of surgical repair techniques and outcomes. Dis Colon Rectum 2013;56:374-83.

6. Netsch C, Bach T, Gross E, et al. Rectourethral fistula after high-intensity focused ultrasound therapy for prostate cancer and its surgical management. Urology 2011;77:999-1004.

7. Iacopini F, Di Lorenzo N, Altorio F, et al. Over-the-scope clip closure of two chronic fistulas after gastric band penetration. World J Gastroenterol 20107;16:1665-9.

8. Teitelbaum JE, Gorcey SA, Fox VL. Combined endoscopic cautery and clip closure of chronic gastrocutaneous fistulas. Gastrointest Endosc 2005;62:432-5.

9. Duddempudi S, Ghevariya V, Singh M, et al. Treatment of persistently leaking post PEG tube gastrocutaneous fistula in elderly patients with combined electrochemical cautery and endoscopic clip placement. South Med J 2009;102:585-8.

10. Farach SM, Danielson PD, McClenathan DT, et al. Endoscopic closure of persistent gastrocutaneous fistula in children. Pediatr Surg Int 2015;31:277-81.

11. Kirschniak A, Kratt T, Stuker D, et al. A new endoscopic over-the-scope clip system for treatment of lesions and bleeding in the GI tract: First clinical experiences. Gastrointest Endosc 2007;66:162-7.

12. Repici A, Arezzo A, De Caro G, et al. Clinical experience with a new endoscopic over-thescope clip system for use in the GI tract. Dig Liver Dis 2009;41:406-10.

13. Parodi A, Repici A, Pedroni A, et al. Endoscopic management of GI perforations with a new over-the-scope clip device (with videos). Gastrointest Endosc 2010;72:881-6.

14. Mercky P, Gonzalez JM, Aimore Bonin E, et al. Usefulness of over-the-scope clipping system for closing digestive fistulas. Dig Endosc 2015;27(1):18-24.

15. Surace M, Mercky P, Demarquay JF, et al. Endoscopic management of GI fistulae with the over-the-scope clip system (with video). Gastrointest Endosc 2011;74(6):1416-1419. 
Case: Combined endoscopic cautery and over-the-scope-clip closure for RUF repair

\section{Figures and Tables}

Fig. 1. Contrast barium enema showing persistence of the rectourethral fistula.

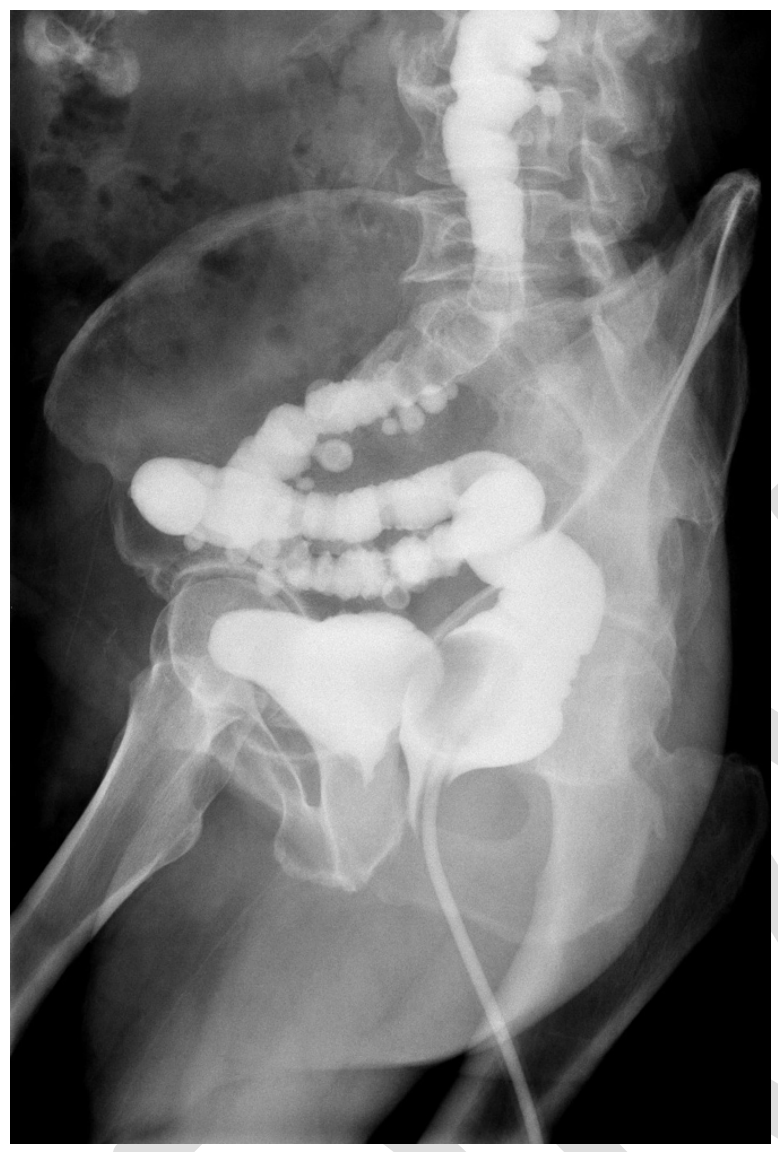


Case: Combined endoscopic cautery and over-the-scope-clip closure for RUF repair

Fig. 2. (A) Fistula opening identified before treatment. (B) Fistula opening after cautery. (C) Placement of OTSC over fistula tract. (D) Completed clip closure.

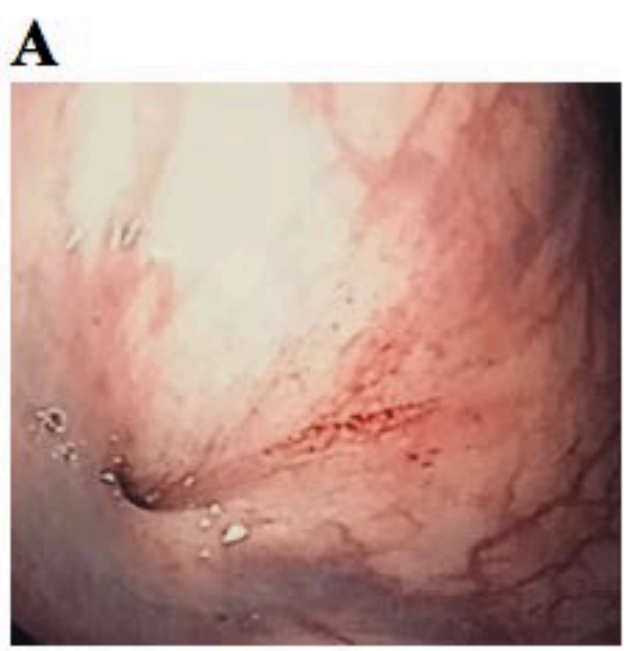

C

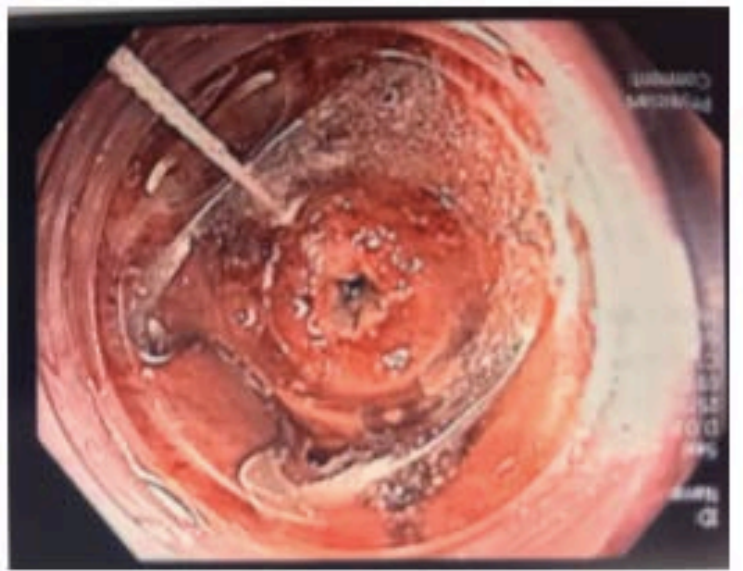

B

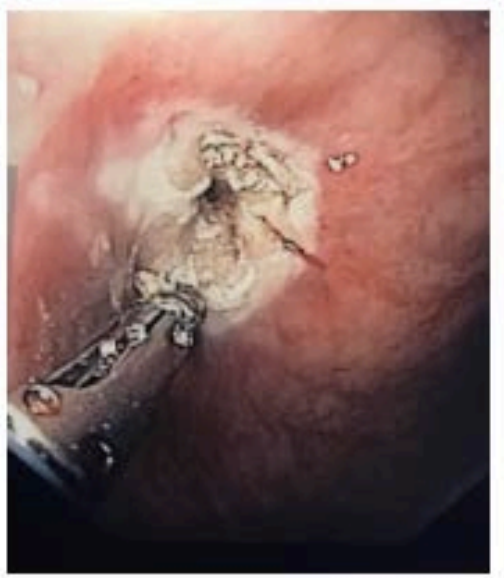

D

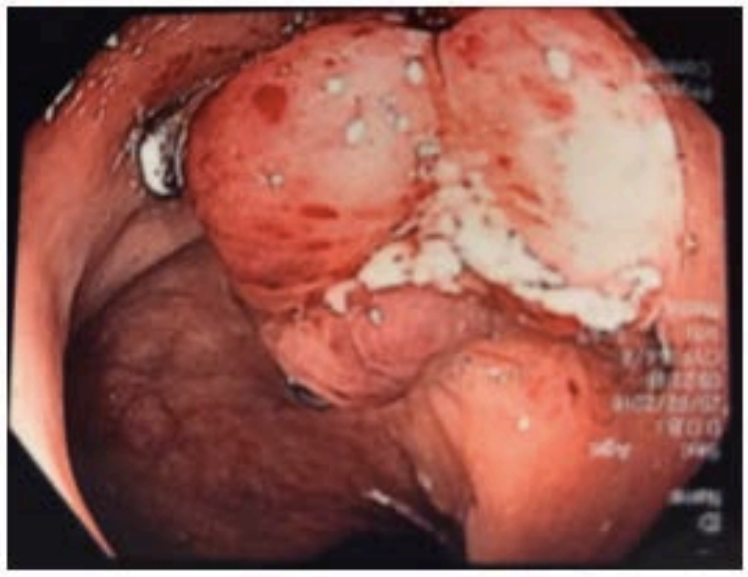


Case: Combined endoscopic cautery and over-the-scope-clip closure for RUF repair

Fig. 3. Contrast barium enema showing resolution of the rectourethral fistula.

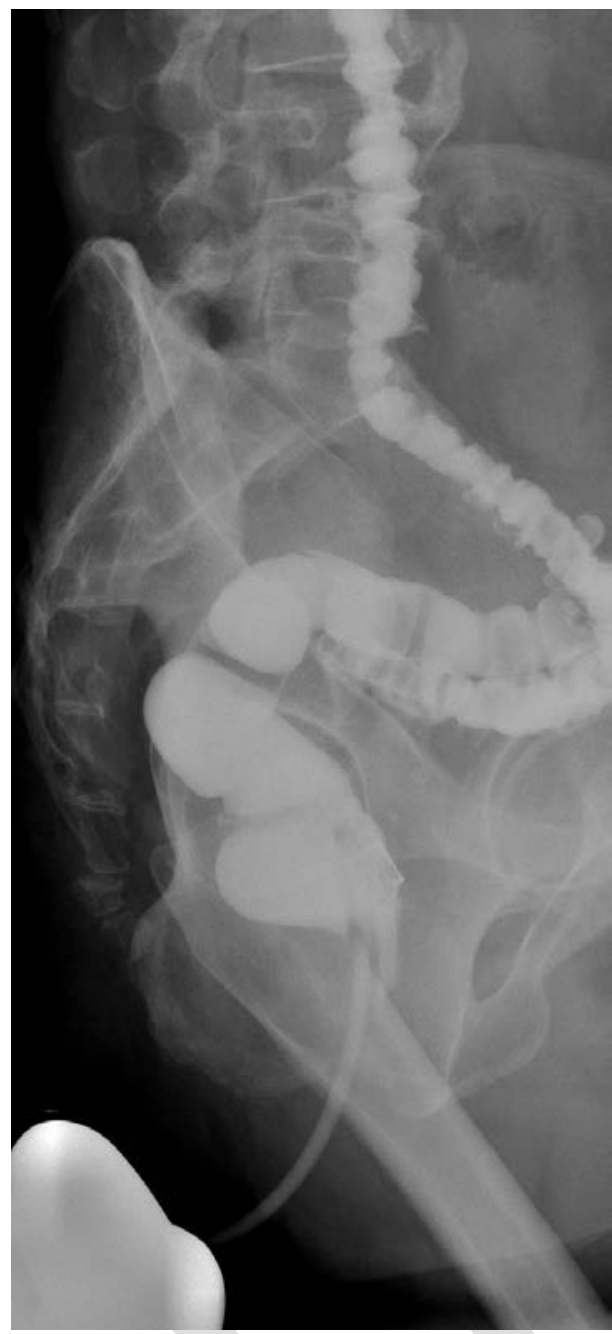

